\title{
Management of acute rhinosinusitis in primary care: changing paradigms and the emerging role of intranasal corticosteroids
}

\author{
*Dermot Ryan ${ }^{\mathrm{a}, \mathrm{b}}$ \\ a Woodbrook Medical Centre, Loughborough, Leicestershire, UK \\ ${ }^{\mathrm{b}}$ Research Fellow, Department of General Practice, University of Aberdeen, Scotland, UK
}

Received 17th September 2007; revised version received 22nd April 2008; accepted 26th May 2008; online 12th August 2008

\begin{abstract}
Primary care physicians are frequently confronted with patients suffering from symptoms of acute rhinosinusitis (RS), and may resort to antibiotic management guided by traditional treatment approaches or in response to patient expectations. Acute RS symptoms are now thought to be caused largely by host inflammatory responses and not solely by infectious agentsas was once assumed. An increasing amount of evidence confirms that, for routine treatment of uncomplicated acute RS, antibiotics are of little or no benefit in most cases. Further, inappropriate prescription of antibiotics for acute RS contributes to the worsening problem of antibiotic resistance, puts patients at risk of unnecessary side effects, and drives up the cost of medical care. Thereforel treatment goals are shifting toward efforts to quell the inflammatory process in the sinuses and restore normal sinus functioning. Glinical stadies with intranasal corticosteroids support their usefulness as monotherapy or adjunctive therapy in relieving symptoms of acute RS, and recently published treatment guidelines recommend their use as a general management measure for RS, witb antibiot)s reserved only for more severe cases when a bacterial aetiology is highly suspected. This changing paradigm reflects current understanding of acute RS pathophysiology, and addresses the need to curtail unnecessary antibiotic usage.

(C) 2008 General Practice Airways Group. All rights reserved,

D Ryan. Prim Care Resp J 2008; 17(3): 148-155.

doi:10.3132/pcrj.2008.00050
\end{abstract}

Keywords antibiotics, corticosterojds, intranasal, primary care, acute rhinosinusitis

\section{Contents}

Introduction

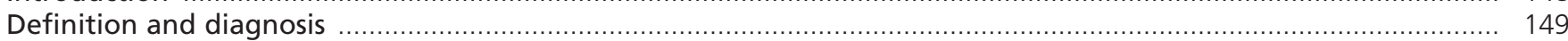

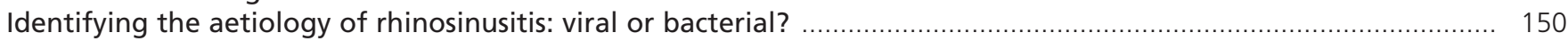

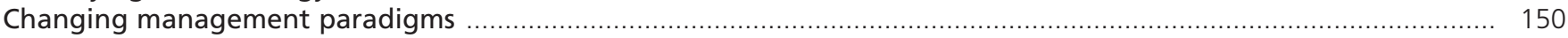

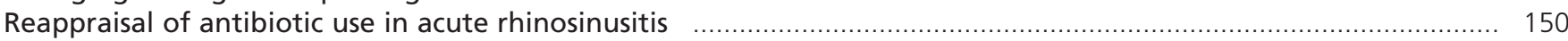

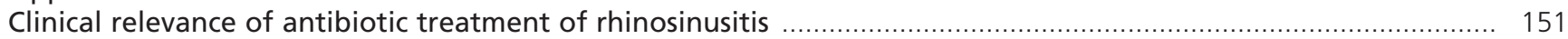

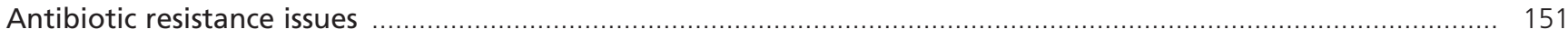

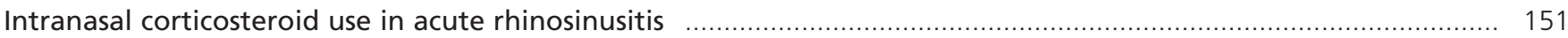

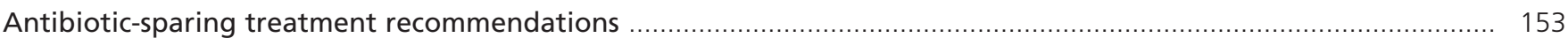

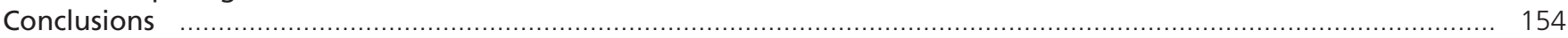

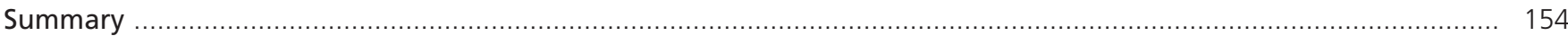

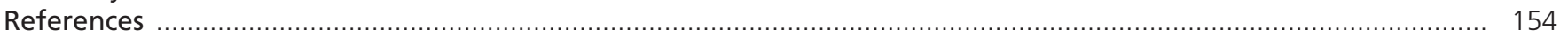

\section{Introduction}

The term 'sinusitis' has traditionally been used to describe infectious conditions of the contiguous nasal and paranasal sinuses, but it is now recognised that sinus infection is almost always accompanied by inflammation of the nasal passages (rhinitis) - hence 'rhinosinusitis' (RS) is now the accepted terminology for this inflammatory symptom complex. ${ }^{.}$Acute RS refers to symptoms (i.e. nasal blockage/obstruction/

\footnotetext{
* Corresponding author: Woodbrook Medical Centre, 28 Bridge Street, Loughborough, LE11 1NH, UK.

Tel: +44 (0)1509239166 Fax: +44(015092396490 Email: dermotryan@doctors.org.uk
} 
congestion or nasal discharge/postnasal drip with or without facial pain/pressure and reduction or loss of smell) lasting for less than 12 weeks, that completely resolve. In contrast, the symptoms of chronic RS persist for more than 12 weeks without complete resolution. ${ }^{2}$

Epidemiologic studies commonly refer to RS without differentiating between acute and chronic illness. ${ }^{2}$ In the United States, acute and chronic RS affects an estimated $14 \%$ of the population, ${ }^{3}$ and is associated with annual medical expenditure of $\$ 3.5$ billion. ${ }^{4}$ In Europe, at least one episode of acute RS annually was reported by about $8.4 \%$ of the Dutch population based on data for 1999. ${ }^{2}$ An analysis of workplace-related cost burdens associated with various diseases ranked RS ninth among the top 10 most expensive physical diseases. ${ }^{5}$

According to one estimate, almost $90 \%$ of patients with viral rhinitis (common cold) have paranasal sinus involvement detectable by computed tomography (CT) scan. ${ }^{6}$ Logically the common cold could be more accurately labeled as acute viral RS. ' Studies suggest a positive bacterial culture is found in only about $0.5 \%$ to $2 \%$ of viral RS cases. ${ }^{7}$ The most common precursor to acute RS accompanied by a bacterial infection is viral upper respiratory infection. ${ }^{8}$

In line with the (mistaken) belief that bacterial infection is the major aetiological factor, antibiotic treatment has become routine practice for patients presenting with symptoms of acute RS. Primary care physicians prescribe antibiotics for $85^{\circ}$ - $98 \%$ of patients with suspected acute RS, 90 fuelled by patients' experiences, expectations and demand.10

Defined diagnostic and treatment guidelines should be followed for the accurate evaluation of acute RS and its effective management. ${ }^{2}$ This practice is particularly important for primary care physicians, who treat $80-90 \%$ of patients with sinus complaints." This review will provide a clinical overview of acute RS, with an emphasis on accurate diagnosis, natural history of the illness, and current treatment recommendations for primary care physicians.

\section{Definition and diagnosis}

The definition of rhinosinusitis is swelling of the mucous membrane in both the nose and sinuses. ${ }^{1}$ Acute RS is commonly precipitated by blockage of the sinus ostia (from the Latin word for 'opening').12 Normal sinus function depends on the patency of the sinus ostia, as well as mucociliary clearance mechanisms. ${ }^{11}$ Failure of sinus drainage leads to the build-up of mucus in the sinuses.

The traditional view of acute RS as primarily a bacterial infectious process has been challenged by recent research that places more emphasis on host inflammatory response. It is now thought that host defense mechanisms to viral infection trigger chemotaxis and activation of inflammatory
Figure 1. Symptom markers for clinical diagnosis of acute rhinosinusitis (presence of two or more symptoms, one of which should be either congestion/blockage or anterior discharge/postnasal drip). ${ }^{2}$

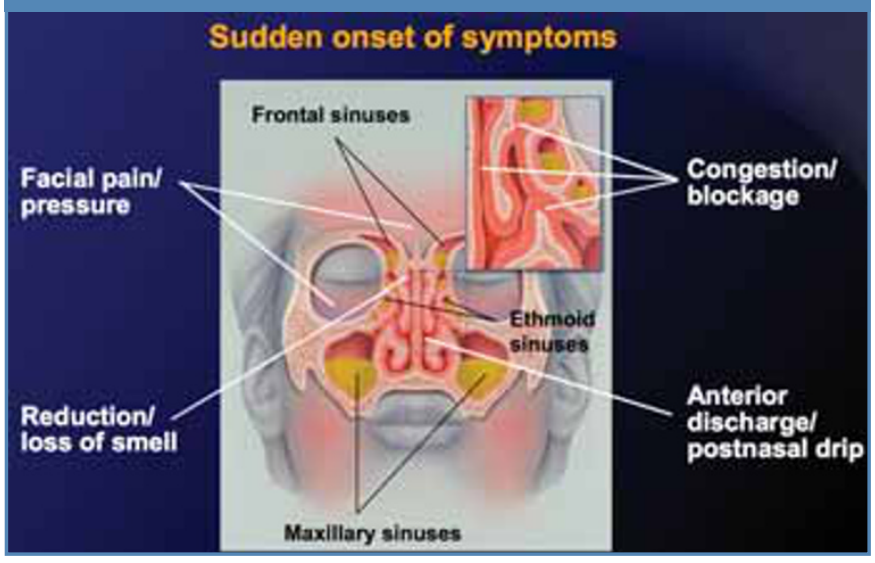

cascade reactions leading to $\mathrm{RS}$, rather than the cytotoxic activities of the vifus as was previously believed." The accumulation of /ipflammatory mediator cells and mucosal oedema, can Pead to ostial occlusion and increased susceptibility to bacterial superinfection within the sinuses. Even in the absence of infection, ostial occlusion itself causes pro-inftammatory changes by impeding normal gas exchange within the sinuses and impairing the function of immune System defense mechanisms."

In the primary care setting, diagnosing acute RS definitively, and differentiating between viral, bacterial, or allergic causes, can be difficult, given the non-specificity of symptoms and the lack of convenient and reliable diagnostic tools. Local symptoms of RS include nasal blockage, congestion or stuffiness, nasal discharge or postnasal drip (which is often mucopurulent), facial pain or pressure, headache, and reduction or loss of smell. ${ }^{2}$ Other symptoms include drowsiness, malaise, fever, halitosis, dental pain, pharyngitis, and otologic symptoms (e.g. ear fullness and clicking). ${ }^{1,2}$ The symptomatology is essentially the same in patients with acute or chronic RS, although symptoms generally are more distinct and frequently more severe in acute RS. ${ }^{2}$

In the most recent European Position Paper on Rhinosinusitis and Nasal Polyps (EP ${ }^{3}$ OS 2007), ${ }^{2}$ acute/intermittent RS is defined as the sudden onset of two or more relevant symptoms for $<12$ weeks (Figure 1), at least one of which is:

- Nasal blockage/obstruction/congestion, OR

- Nasal discharge (anterior/posterior nasal drip); AND

\pm Facial pain/pressure,

\pm Reduction/loss of sense of smell.

Because acute RS often occurs in individuals with underlying seasonal or perennial rhinitis, ${ }^{13}$ patients should be 
questioned about allergic symptoms, such as sneezing, watery rhinorrhea, nasal itching, and ocular itching and tearing. ${ }^{2}$ In one study of young adults with acute maxillary RS, skin test reactions were positive for airborne pollens typically implicated in allergic rhinitis occurring during the spring and autumn pollen seasons, as well as for animal dander. ${ }^{13}$

Acute RS is typically a discrete clinical event. There may be more than one annual episode, but classification as acute intermittent RS requires complete resolution of symptoms between episodes. Chronic RS is differentiated by persistence of two or more symptoms for $>12$ weeks. ${ }^{2}$

\section{Identifying the aetiology of acute rhinosinusitis: viral or bacterial?}

While clinical findings may support a general diagnosis of acute RS, they do not differentiate between bacterial and viral aetiologies. Most cases of acute bacterial RS are preceded by viral infection, further complicating the distinction. ${ }^{14}$ The duration of symptoms can be an important diagnostic indicator: symptoms of less than 10 days' duration should generally be presumed to be viral acute RS, or common cold, which is normally self-limiting. Non-viral acute RS is suspected when symptoms worsen after five days, or persist for longer than 10 days. ${ }^{2}$ Purulent drainage within the middle meatus, while strongly diagnostic for acute RS in general, does not distinguish between viral and bacterial pathology." Berg and Carenfelt ${ }^{15}$ correlated a number of symptoms with possible bacterial aetiology, including a history of primarity unilateral purulent nasal discharge, history of facial pain with unilateral predominance, and purulent nasal discharge andlor pus in the nasal cavity.

Assessment of the severity of symptoms in patients with acute RS is helpful in determining appropriate initial treatment. ${ }^{2}$ The severity of acute RS can be evaluated with a visual analogue scale (VAS) (Figure 2) whereby the patient marks on a $10 \mathrm{~cm}$ VAS his/her perception of their symptom severity, with categories of mild, moderate, and severe assigned according to set VAS measurements. A VAS score $>5$ has been associated with an impaired quality of life., 2,16

Unfortunately, no single test or investigation is available for the general practitioner (GP) to confirm a diagnosis. A raised C-reactive protein (CRP) level (10-50 $\mathrm{mg} / \mathrm{dL}$ ) may suggest a somewhat greater likelihood of bacterial involvement, particularly beyond the first week of illness. ${ }^{2,17}$ An elevated erythrocyte sedimentation rate (ESR) may also contribute to the diagnosis. ${ }^{18,19}$ More complex investigations are possible in secondary or tertiary care settings with access to diagnostic tools such as CT scanning, ultrasound examination, sinus puncture, and nasal endoscopy, but these should be reserved for severely ill patients. Sinus $\mathrm{x}$-rays are no longer considered useful. ${ }^{2}$ However, each of these techniques has limitations,
Figure 2. Rhinosinusitis severity assessment using a visual analogue scale (VAS). ${ }^{2}$

How troublesome are your symptoms of rhinosinusitis?

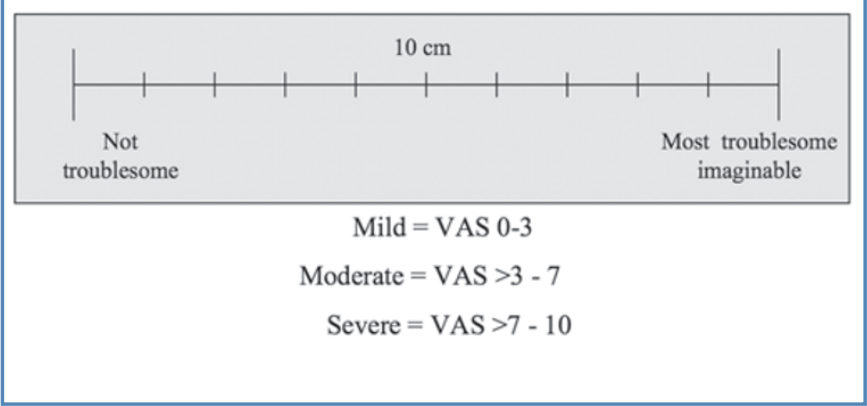

and none are indicated for routine diagnostic investigation or management of acute RS in the primary care setting. ${ }^{11,14}$

Sinus puncture with culture is still considered the 'gold standard' for diagnosing maxillary bacterial acute RS, but the procedure is painful and requires significant expertise to avoid complications. ${ }^{14}$ Vh reality, its usefulness is limited in clinical practice, particularly in primary care. Its' use may be indicated in those who are immunocompromised or who exhibit clinical deterioration with severe local or systemic symptoms when precisediagnosis is essential and microbiological sensitivities need to be identified. ${ }^{11}$

\section{Changing management paradigms}

The twin goals of RS management are to shrink oedematous tissues and to restore ostial patency which allows drainage of mucus to resolve symptoms and reduce the risks of bacterial superinfection. General measures that can be recommended include adequate fluid intake, saline nasal sprays, analgesics, and oral or topical decongestants.,11 Topical decongestants may be helpful in relieving acute symptoms, but they should not be used for longer than three to five days because of the risk of causing rhinitis medicamentosa. ${ }^{11}$ Saline administration via spray, aerosol, or irrigation is a simple and inexpensive (but often overlooked) means of softening viscous secretions and providing some relief from congestion. Antihistamines have no efficacy in acute RS and are not recommended, although they are frequently prescribed erroneously and purchased over-the-counter to relieve symptoms. ${ }^{11}$

\section{Reappraisal of antibiotic use in acute rhinosinusitis}

Antibiotics are still routinely prescribed for patients with symptoms of acute RS, even when the cause is likely to be viral. ${ }^{20}$ However, two issues have become increasingly relevant in challenging this practice. Firstly, the use of antibiotics has been reappraised because few episodes of uncomplicated RS 
are of bacterial aetiology, thus encouraging a similar approach to the management of acute otitis media. ${ }^{21}$ Even when bacterial acute RS is confirmed, an estimated $50-70 \%$ of cases would be expected to resolve over the course of seven to 10 days without antibiotic treatment. ${ }^{21} \mathrm{~A}$ second issue, and one of growing importance, is the global problem of bacterial resistance, propagated to a large extent by inappropriate and excessive prescribing of antibiotics. ${ }^{20}$

\section{Clinical relevance of antibiotic treatment of} rhinosinusitis

While numerous studies have investigated antibiotic treatment of acute RS, few have been able to show any significant benefit. This is not surprising, given that acute RS is usually a self-limiting disease rarely complicated by bacterial infection. ${ }^{22,23}$ One meta-analysis reported that two-thirds of subjects with RS experienced spontaneous improvement or cure without receiving antibiotics. ${ }^{24}$

To evaluate clinical studies of antibiotic therapy in acute $R S$, it is important to analyse the inclusion criteria used to diagnose the disease, and whether or not bacterial aetiology was confirmed by an objective technique. Many clinical trials, $^{25-27}$ and a number of meta-analyses, ${ }^{24,28,29}$ limited inclusion to subjects in whom a bacterial aetiology was confirmed by laboratory studies or imaging procedures. These studies would be expected to have a greater likelihood of demonstrating benefit from antibiotic therapy. One meta-analysis ${ }^{24}$ included data on 2717 subjects from 27 trials, many of which required confirmation of bacterial disease. Overall, antibiotio treatment decreased the incidence of clinical failures J defined as no change in, or worsening of, signs and symptomstby half (risk ratio: $0.54,95 \% \mathrm{Cl} 0.37-0.79$ ), with amoxicillin shown to be equally effective as more expensive antibiotics.

Studies more representative of general medical practice with patients diagnosed solely on clinical evaluation $23,30,31$ did not report any significant difference in recovery outcomes between antibiotic and placebo (or symptomatic management). De Sutter et al. ${ }^{30}$ reported successful outcomes (disappearance of most distressing symptoms at Day 10) in $35 \%$ of patients treated with amoxicillin and $29 \%$ of patients treated with placebo (RR: $1.14,95 \% \mathrm{Cl} 0.92-1.42$ ). Stalman et al. ${ }^{23}$ identified 88 clinical trials of antibiotic treatment of acute RS published between 1966 and 1996, only three of which were placebo-controlled, double-blind, randomised studies in adults with acute maxillary sinusitis, and these were published between 1973 and 1978. Only one of these three suggested a greater benefit from antibiotic treatment, and this trial assessed bacteriologic cure based on nasal culture findings, a finding which does not directly correlate with sinus flora. ${ }^{23}$

These findings support the growing consensus that, for general medical practice, treatment goals should be focused primarily on alleviating symptoms, combating local inflammation, and improving sinus drainage, rather than on trying to cure a presumed bacterial infection.

\section{Antibiotic resistance issues}

Worldwide surveillance data confirm that antibiotic resistance is increasing at varying rates in different regions. ${ }^{32}$ Wide variations in antibiotic usage patterns, including both sales volume and antibiotic class distribution, have been observed among European Union countries. ${ }^{33}$

The most common pathogens isolated from infected maxillary sinuses in adults are Streptococcus pneumoniae (20$43 \%)$, Haemophilus influenzae (22-35\%), and Moraxella catarrhalis (2-10\%). Other, less frequent, causative organisms include other streptococcal species, anaerobic bacteria, and Staphylococcus aureus. ${ }^{34}$ Similar organisms are found in children, although the distribution is slightly different - S. pneumoniae $(25-30 \%), H$. influenzae $(15-20 \%)$, and $M$. catarrhalis (15-20\%). ${ }^{34}$ An alarming pattern of increasing global resistance has been observed-among $S$. pneumoniae isolates, particularly to amoxicillin, Other beta-lactam antibiotics, trimethoprim/sulfamethoxazole, and macrolides. ${ }^{32}$ Within the United States, findings for 1998 to 2000 from the Alexander Project (a surveillance programme of antibiotic resistance in adult community-acquired respiratory tract infections) demonstrated that $25 \%$ of S. pneumoniae isolates were penicillin resistant, and $12 \%$ were of intermediate susceptibility. Considerable rates of resistance were also observed for trimethoprim/sulfamethoxazole (36\%), macrolides (28\%), doxycycline $(21 \%)$, and clindamycin $(10 \%) .35$

Overuse of antibiotics has often been correlated with increased organism resistance. ${ }^{36,37}$ However, resistance may be reversible when antibiotic use is restrained. ${ }^{38}$ Countries with the most reserved prescribing patterns have relatively lower rates of antibiotic resistance. ${ }^{39}$

The type of antibiotic used is just as important as the amount prescribed. Broad-spectrum antibiotics are often used when a narrow-spectrum agent would be just as effective. A study based on data from the National Ambulatory Medical Care Survey in the United States reported that the use of broadspectrum agents, as a percentage of all antibiotics prescribed for adults, increased from $24 \%$ in 1991 to $48 \%$ in 1999 $(p<0.001) .{ }^{40}$ In 1999, 22\% (adult) and 14\% (paediatric) of prescriptions for broad-spectrum antibiotics were for conditions with a probable viral aetiology (e.g. common cold, unspecified upper respiratory tract infections, acute bronchitis). ${ }^{40}$

\section{Intranasal corticosteroid use in acute rhinosinusitis}

The concept of using corticosteroid agents in the management of a potentially infectious condition seems contrary to most medical school training - namely that corticosteroids reduce host immunity and might facilitate 
infection. However, it is now appreciated that concomitant use of these agents either topically (as in acute otitis media with otorrhea or chronic otitis externa ${ }^{41,42}$ ) or systemically (as in the management of an infective exacerbation of chronic obstructive pulmonary disease ${ }^{43,44}$ ) is effective and reduces the duration of disease. The same concept is now becoming evident for RS management.

The rationale for intranasal corticosteroid (INS) administration in acute RS is based on the alleviation of inflammation and oedema of the nasal mucosa, nasal turbinates, and sinus ostia. Attenuating the inflammatory response and reducing mucosal swelling would be expected to promote more efficient drainage and improved aeration of the sinuses, thereby lessening the duration and severity of RS symptoms and reducing the risk of superinfection. ${ }^{45}$

Earlier clinical trials demonstrating the theoretical benefits of INS in acute RS have since been corroborated by a number of randomised controlled studies (Table 1).45-51 One of the earliest studies was a double-blind parallel trial of 175 adults with radiographically-documented acute maxillary sinusitis. ${ }^{46}$ Subjects were initially randomised to treatment with amoxicillin/clavulanate combined with either flunisolide nasal spray or placebo nasal spray, three times daily, for three weeks (Phase 1). During Phase 2, treatment consisted of flunisolide or placebo nasal spray alone for an additional four weeks. Patients' global assessments of overall treatment effectiveness

Table 1. Clinical trials of intranasal corticosteroids as monotherapy or adjunct therapy in acute rhinosinusitis.

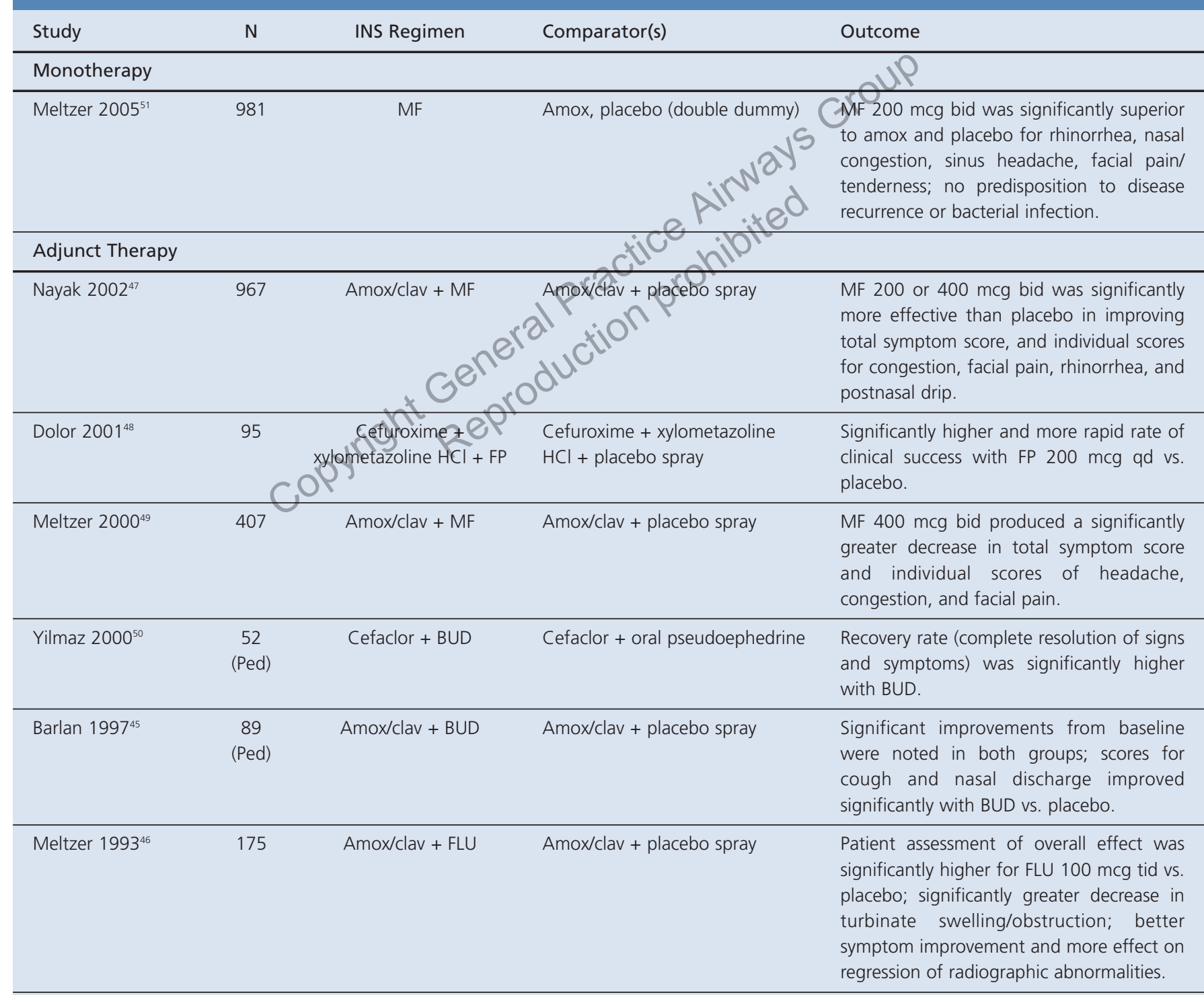

MF = mometasone furoate; Amox = amoxicillin; Clav = clavulanate; bid = twice daily; FP = fluticasone propionate; $q$ d = once daily; Ped = paediatric; BUD = budesonide; $\mathrm{FLU}=$ flunisolide; tid $=$ three times daily. 
(VAS ratings) favoured flunisolide over placebo after both Phase $1(p=0.007)$ and Phase $2(p=0.08)$.

In another early double-blind study involving 89 children with acute RS, subjects treated for three weeks with a combination of amoxicillin/clavulanate and intranasal budesonide showed significantly greater improvements in symptoms of cough and nasal discharge compared with patients receiving antibiotic therapy and placebo spray $(p<0.05) .^{45}$ Subsequent studies in both adults ${ }^{47-49}$ and children ${ }^{50}$ have reported greater symptom improvement in subjects treated with regimens containing an INS.

To date, only one study has reported the efficacy of INS monotherapy in patients with acute RS. Meltzer et al. ${ }^{51}$ conducted a large trial involving 981 subjects with uncomplicated acute RS. In this double-blind, double-dummy, placebo-controlled prospective study, subjects were randomised to treatment with mometasone furoate nasal spray (MFNS) 200 mcg once or twice daily for 15 days or amoxicillin $500 \mathrm{mg}$ three times daily for 10 days. As early as Day 2, MFNS 200 mcg twice daily showed significantly greater improvement in total symptom score relative to both placebo $(p<0.001)$ and amoxicillin $(p=0.002)$.

Some suspicions still linger among patients and clinicians as to the safety of INS, particularly in children. The available evidence fails to suggest any routine risk of growth suppression with the use of INS in children, especially with newer compounds having extremely low systemic availability with intranasal use (e.g. MFNS, fluticasone propionate).5.5.
Common side effects of INS include epistaxis, nasal dryness, pharyngitis, and cough. ${ }^{53-57}$

\section{Antibiotic-sparing treatment recommendations}

There are specific instances in which antibiotics should be used in the treatment of acute RS - i.e. patients with meningeal or orbital complications, and those who are immunocompromised or hospitalised. ${ }^{20}$ Bacterial RS also poses the risk of rare complications such as chronic RS, meningitis, intracranial abscess, and orbital cellulitis or abscess, as well as exacerbation of asthma or bronchitis. ${ }^{7.21}$

For the routine management of acute RS, a treatment algorithm from $E P^{3} O S 2007^{2}$ provides guidance for appropriate antibiotic implementation based on clinical factors alone. According to this algorithm, antibiotic use should be reserved for RS symptoms that persist or worsen after five days, or worsen after 10 days, and even then, only if symptoms are severe (feyer $>38^{\circ}$ or severe pain) (Figure 3). ${ }^{2}$ Intranasal corticosteroids are recommended for all cases with moderate (mondfherapy) to severe (in combination with antibiotics) symptomatology. Symptoms of $<5$ days' duration or which start to improve should be managed symptomatically. Specialist referral may be indicated when INS Cuse does not lead to improvement after 14 days, if antibiotic/INS therapy produces no improvement after 48 Chours, or if complications (high fever, ocular or periorbital symptoms, or signs of meningeal irritation) appear.

Figure 3. Treatment algorithm for adults with acute rhinosinusitis seen in primary care setting. ${ }^{2}$

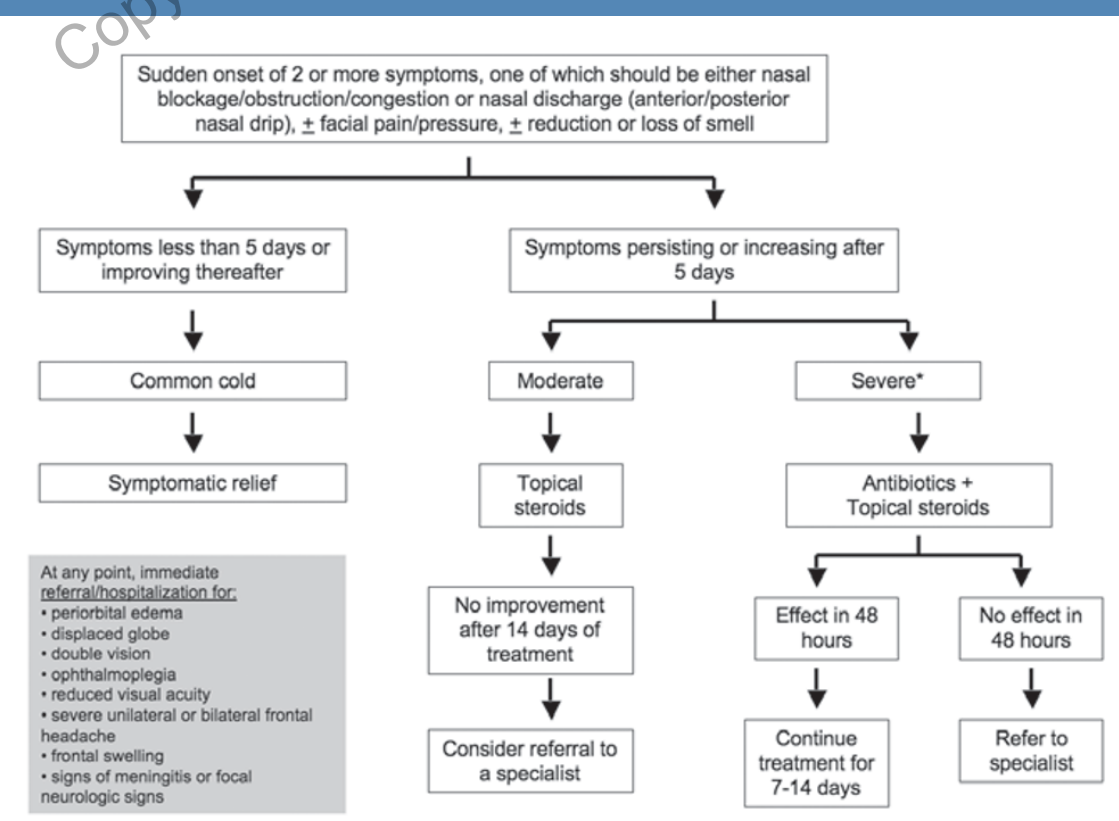

${ }^{*}$ Fever $>38^{\circ} \mathrm{C}$, severe pain 
Antibiotic therapy should be chosen for expected efficacy against the most likely causative organisms, namely $S$. pneumoniae, $H$. influenzae, and $M$. catarrhalis. ${ }^{34}$ Resistance patterns of these pathogens vary greatly geographically, and local antibiograms (antibiotic prescribing guidelines) should play a major role in the selection of appropriate therapy. No single antibiotic choice can be universally recommended. Most national guidelines and the most recent Cochrane review on antibiotic use in acute maxillary sinusitis advocate the use of amoxicillin (with or without clavulanate, which provides for better coverage against $H$. influenzae and $M$. catarrhalis) for uncomplicated bacterial acute RS. ${ }^{11,14,29}$ Highdose amoxicillin (e.g. $80-90 \mathrm{mg} / \mathrm{kg} / \mathrm{day}$, maximum 3 grams/day) can still be effective against resistant organisms and might be considered in regions where $S$. pneumoniae resistance is high. ${ }^{11}$

\section{Conclusions}

In conclusion, our growing understanding of the pathophysiology of RS, and the pressing need to curtail excessive antibiotic usage, are shifting treatment guidelines away from infection-targeted management. In most cases, the symptoms of acute RS are probably caused by host inflammatory processes countering viral infection, rather than by bacterial superinfection. Intranasal corticosteroids have proven efficacy in attenuating this inflammatory response, and in helping to restore ostial patency and normal sinus function. The ase of INS can be recommended for most cases of acute RS, either alone or as an adjunct to antibiotic therapy, and are an important element of the new RS management paradigm.

\section{Summary}

Acute rhinosinusitis (RS) in most cases is a host inflammatory response to a viral infection rather than the direct effects of bacterial infection. Evidence confirms the lack of efficacy of antibiotics for treatment of acute RS. Inappropriate prescribing contributes to antibiotic resistance and unwanted adverse events. Current treatment goals are to arrest the inflammatory process in the sinuses and to restore normal sinus function. Intranasal corticosteroids are useful in relieving the symptoms of acute RS; treatment guidelines recommend their use, with antibiotics reserved for cases where a bacterial aetiology is likely.

\section{Acknowledgement and authorship declaration}

The author (DR) wishes to thank Matthew Cahill (MC) and Sandra Westra (SW) for their assistance with this paper. At the time of writing, MC was an employee of, and SW was contracted to, Adelphi Inc. After initial concept discussions, Adelphi presented an outline to DR (which the editors have not seen) which was rejected and subsequently re-written by the author. Neither MC nor SW satisfy full ICJME criteria for authorship. SW provided writing support as and when necessary. MC provided editorial support in terms of reference checking, journal styling and submission of the manuscript. The assistance of SW and MC was funded by
Schering-Plough. DR was involved with the initial concept of the paper, was extensively involved with the writing, and retained full editorial control throughout the development of the manuscript. Final approval was solely endorsed by the author

\section{Funding}

This manuscript was supported by a grant from Schering-Plough Corp. to fund editorial and secretarial assistance. The author did not receive any payment for writing the manuscript.

\section{Conflict of interest declaration}

Dermot Ryan has provided consultancy services for, lectured on behalf of, or had attendance at conferences subsidised by, Altana Pharma, AstraZeneca, Boehringer Ingelheim, Teva, Ivax, Schering Plough, Merck Sharpe and Dohme, GlaxoSmithKline, Pharmacia and Novartis.

\section{References}

1. Lanza DC, Kennedy DW. Adult rhinosinusitis defined. Otolaryngol Head Neck Surg 1997;117(3 Pt 2):S1-S7

2. Fokkens W, Lund V, Mullol J, on behalf of the European Position Paper on Rhinosinusitis and Nasal Polyps group. European Position Paper on Rhinosinusitis and Nasal Polyps 2008. Rhinology 2007;(Suppl 20):1-136

3. Slavin RG. Nasal polyps and sinusitis. JAMA 1997;278(22):1849-54

4. Ray NF, Baraniuk JN, ThamênM, et al. Healthcare expenditures for sinusitis in 1996: contributions of asthma, rhinitis, and other airway disorders. J Allergy Clin Immunol 1999; 103(3 Pt 1):408-14

5. Goetzel RZ, Hawkins K, Ozminkowski RJ, Wang S. The health and productivity cost burden of the "top 10" physical and mental health conditions affecting six varge U.S. êmployers in 1999. J Occup Environ Med 2003;45(1):5-14.

Gwaltney NM, Phillips DC, Miller RD, Riker DK. Computed tomographic study of the Common cold. N Engl J Med 1994;330(1):25-30

7. Gwaltney JM Jr. Acute community-acquired sinusitis. Clin Infect Dis 1996;23(6) 1209-23.

8. Osguthorpe JD. Adult Rhinosinusitis: diagnosis and management. Am Fam Physician 2001;63(1):69-76.

9. Gonzales R, Steiner JF, Lum A, et al. Decreasing antibiotic use in ambulatory practice. Impact of a multidimensional intervention on the treatment of uncomplicated acute bronchitis in adults. JAMA 1999;281(16):1512-19.

10. Dosh SA, Hickner JM, Mainous AG III, Ebell MH. Predictors of antibiotic prescribing for nonspecific upper respiratory infections, acute bronchitis, and sinusitis. J Fam Pract 2000;49(5):407-14

11. Winstead W. Rhinosinusitis. Prim Care Clin Office Pract 2003;30(1):137-54.

12. Zalmanovici A, Yaphe J. Steroids for acute sinusitis. Cochrane Database Syst Rev 2008;18(2):CD005149.

13. Savolainen S. Allergy in patients with acute maxillary sinusitis. Allergy 1989;44:116-22.

14. Desrosiers M, Klossek J-M, Benninger M. Management of acute bacteria rhinosinusitis: current issues and future perspectives. Int I Clin Pract 2006;60(2):190-200

15. Berg $O$, Carenfelt $C$. Analysis of symptoms and clinical signs in the maxillary sinus empyema. Acta Otolaryngol 1988;105(3-4):343-9.

16. Lim M, Lew-Gor S, Darby Y, Brookes N, Scadding G, Lund VJ. The relationship between subjective assessment instruments in chronic rhinosinusitis. Rhinology 2008;45(2):144-7

17. Melbye $H$, Stocks N. Point of care testing for C-reactive protein. A new path for Australian GPs? Aust Fam Physician 2006;35(7):513-16.

18. Lindbaek M, Hjortdahl P. The clinical diagnosis of acute purulent sinusitis in general practice - a review. Brit J Gen Pract 2002;52(479):491-5.

19. Hansen JG, Schmidt $H$, Rosborg J, Lund E. Predicting acute maxillary sinusitis in a general practice population. BMJ 1995;311(6999):233-6.

20. Small $C B$, Bachert $C$, Lund VJ et al. Judicious antibiotic use and intranasal 
corticosteroids in acute rhinosinusitis. Am J Med 2007;120(4):289-94.

21. Poole MD. Acute bacterial rhinosinusitis: clinical impact of resistance and susceptibility. Am J Med 2004;117(Suppl 3A):29S-38S.

22. Leggett JE. Acute sinusitis: When - and when not - to prescribe antibiotics. Postgrad Med 2004;115(1):13-19.

23. Stalman W, van Essen GA, van der Graaf $Y$, de Melker RA. Maxillary sinusitis in adults: an evaluation of placebo-controlled double-blind trials. Fam Pract 1997;14(2):124-9

24. de Ferranti SD, Ioannidis JPA, Lau J, Anninger WV, Barza M. Are amoxicillin and folate inhibitors as effective as other antibiotics for acute sinusitis? A metaanalysis. BMJ 1998;317(7159):632-7.

25. Van Buchem FL, Knottnerus JA, Schrijnemaekers V-J, Peeters MF. Primarycare-based randomised placebo-controlled trial of antibiotic treatment in acute maxillary sinusitis. Lancet 1997;349(9053):683-7.

26. Hansen JG, Schmidt H, Grinsted P. Randomised, double blind, placebo controlled trial of penicillin $\mathrm{V}$ in the treatment of acute maxillary sinusitis in adults in general practice. Scand J Prim Health Care 2000;18(1):44-7.

27. Lindbaek M, Hjortdahl P, Johnsen UL. Use of symptoms, signs, and blood tests to diagnose acute sinus infections in primary care: comparison with computed tomography. Fam Med 1996;2(3):183-8.

28. Diagnosis and Treatment of Acute Bacterial Rhinosinusitis. Summary, Evidence Report/Technology Assessment: Number 9, March 1999. Agency for Health Care Policy and Research, Rockville, MD. Available at: http://www.ahrq.gov/ clinic/epcsums/sinussum.htm. Accessed July 20, 2008.

29. Williams JW Jr, Aguilar C, Cornell J, et al. Antibiotics for acute maxillary sinusitis (Cochrane Review). In: The Cochrane Library, Issue 3, 2004. Chichester, UK: John Wiley \& Sons, Ltd.

30. De Sutter Al, De Meyere MJ, Christiaens TC, Van Driel ML, Peersman W, De Maeseneer JM. Does amoxicillin improve outcomes in patients with purulent rhinorrhea? J Fam Pract 2002;51(4):317-23.

31. Merenstein D, Whittaker C, Chadwell T, Wegner B, D'Amico F. Are antibiotics beneficial for patients with sinusitis complaints? A randomized, double-blind clinical trial. J Fam Pract 2005;54(2):144-51.

32. Felmingham D, Reinert RR, Hirakata $Y$, Rodloff $A$. Increasing prevalence of antimicrobial resistance among isolates of Streptococcus pneumoniae from the PROTEKT surveillance study, and comparative nyitro activity of the ketolide, telithromycin. J Antimicrob Chemother 2002;50(Suppl S1):25-37.

33. Cars $\mathrm{O}$, Mölstad S, Melander A. Variation in antibiotic use in the European Union. Lancet 2001;357(9271):1851-3.

34. Anon JB, Jacobs MR, Poole MD, et al. Sinus and Allergy Health Partnership. Antimicrobial treatment guidelines for acute bacterial rhinosinusitis. Otolaryngol Head Neck Surg 2004;130(Suppl 1):1-45.

35. Jacobs MR, Felmingham D, Appelbaum PC, Grüneberg RN. The Alexander Project 1998-2000: susceptibility of pathogens isolated from communityacquired respiratory tract infection to commonly used antimicrobial agents. J Antimicrob Chemother 2003;5(2):229-46.

36. Seppälä H, Klaukka T, Lehtonen R, Nenonen E, Huovinen P. Outpatient use of erythromycin: link to increased erythromycin resistance in group A streptococci. Clin Infect Dis 1995:21(6):1378-85.

37. Nissinen A, Grönroos P, Huovinen P, et al. Development of beta-lactamasemediated resistance to penicillin in middle-ear isolates of Moraxella catarrhalis in Finnish children, 1978-1993. Clin Infect Dis 1995;21(5):1193-6.

38. Seppälä H, Klaukka T, Vuopio-Varkila J, et al. The effect of changes in the consumption of macrolide antibiotics on erythromycin resistance in group $A$ streptococci in Finland. N Engl J Med 1997;337(7):441-6.

39. Goossens $H$, Ferech M, Vander Stichele R, Elseviers M, for the ESAC Project Group. Outpatient antibiotic use in Europe and association with resistance: a cross-national database study. Lancet 2005;365(9459):579-87.

40. Steinman MA, Gonzales R, Linder JA, Landefeld CS. Changing use of antibiotics in community-based outpatient practice, 1991-1999. Ann Intern Med 2003;138(7):525-53.

41. Dohar J, Giles W, Roland P, et al. Topical ciprofloxacin/dexamethasone superior to oral amoxicillin/clavulanic acid in acute otitis media with otorrhea through tympanostomy tubes. Pediatrics 2006;11(3):e561-9.

42. Osguthorpe JD, Nielsen DR. Otitis externa: review and clinical update. Am Fam Physician 2006;74(9):1510-16.

43. Kunisaki KM, Rice KL, Niewoehner DE. Management of acute exacerbations of chronic obstructive pulmonary disease in the elderly: an appraisal of published evidence. Drugs Aging 2007;24(4):303-24

44. Wood-Baker R, Walters J, Walters EH. Systemic corticosteroids in chronic obstructive pulmonary disease: an overview of Cochrane systematic reviews. Respir Med 2007;101(3):371-7.

45. Barlan IB, Erkan E, Bakir M, Berrrak S, Basaran MM. Intranasal budesonide spray as an adjunct to oral antibiotic therapy for acute sinusitis in children. Ann Allergy Asthma Immunol 1997;78(6):598-601.

46. Meltzer EO, Orgel HA, Backhaus WW, et al. Intranasal flunisolide spray as an adjunct to oral antibiotic therapy for sinusitis. I Allergy Clin Immunol 1993;92(6):812-23

47. Nayak AS, Settipane GA, Pedinoff A, et al. Effective dose range of mometasone furoate, nasal spray in the treatment of acute rhinosinusitis. Ann Allergy Asthma Immuno/ 2002;89(3):271-8.

48. Dolor RJ, Witsell DL, Hellkamp AS, et al. Comparison of cefuroxime with or without intranasal fluticasone for the treatment of rhinosinusitis. The CAFFS Trial: a randomized, controlled trial. JAMA 2001;286(24):3097-105.

49. Meltzer EO, Charous L, Busse WW, Zinreich SJ, Lorber RR, Danzig MR. Added relief in the treatment of acute recurrent sinusitis with adjunctive mometasone furoate nasal spray. J Allergy Clin Immunol 2000;106(4):630-7.

50. Yilmaz G, Varan B, Yilmaz T, Gürakan B. Intranasal budesonide spray as an adjunct to oral antibiotic therapy for acute sinusitis in children. Eur Arch Otorhinolaryngol 2000;257(5):256-9.

51. Meltzer EO, Bachert C, Staudinger $H$. Treating acute rhinosinusitis: comparing efficacy and safety of mometasone furoate nasal spray, amoxicillin, and placebo. J Allergy Clin Immunol 2005;116(6):1289-95.

52. Corren J. Intranasal corticosteroids for allergic rhinitis: How do different agents compare? J Allergy Clin Immunol 1999;104(4Pt1):S144-9.

53. AstraZeneca UK Limited. Rhinocort Aqua Nasal Spray (budesonide): summary of product characteristics [SPC]. Available at URL: http://medicines.org.uk/. Accessed August 23, 2008.

54. Nasarel Nasal Spray [prescribing information]. Miami, FL: Ivax Laboratories, Inc; 2006.

55. Allen and Hanburys. Beconase Aqueous Nasal Spray (beclometasone dipropionate): summary of product characterisitics [SPC]. Available at URL: http://medicines.org.uk/. Accessed August 23, 2007.

56. Schering-Plough Limited. Nasonex (mometasone furoate): summary of product characteristics [SPC]. Available at URL: http://medicines.org.uk/. Accessed August 23, 2007.

57. Sanofi-aventis.Nasacort (triamcinolone acetonide): summary of product characteristics [SPC]. Available at URL: http://medicines.org.uk/. Accessed August 23, 2007.

Available online at http://w w w.thepcrj.org 